\title{
First, do no harm: Advocating for opioid prescribing guidelines in Canadian emergency departments
}

\author{
Kieran Moore, MD, MPh, DTM\&H*; Julia Lew, MS1, BSct; Samantha Buttemer, PGY2, BHSc, MD‡; \\ Lauren Kielstra, MS4, MSc, BSc†
}

The excessive use of prescription opioids, where avoidable, is a major health concern for individual communities and for all of Canada. Globally, Canada is the leader in per-capita prescription opioid consumption, with approximately 360,000 individuals dependent on prescription opioids. ${ }^{1,2}$ In 2015, more Canadians were dependent on prescription opioids than were diagnosed with cancer, and twice as many were dependent on prescription opioids than were injured in motor vehicle accidents in the previous year. ${ }^{3,4}$ It has become progressively more evident that loose prescribing of prescription opioids feeds into a complex societal interaction that increases individual exposure to and risk of opioids, and may lead to increased use and abuse. Opioid dependence, which does develop into abuse and addiction, is a multifaceted illness that imposes significant burdens on individuals, communities, and health care systems. Urgent and coordinated action is vital to address this widespread phenomenon.

Health care providers must take ownership of their contribution to this issue and, moving forward, must adopt new strategies to correct the problems. Emergency physicians are by no means the only physicians contributing to overprescribing; however, as prescribers who often are unable to follow up on our patients, we recognize the need for decreased variability amongst emergency physicians' practices. To begin, Canadian emergency departments (EDs) should adopt opioid prescribing guidelines to standardize care and reduce harm. Although guidelines are not generally sufficient to create change, they are an important first step in coordinating action.

Currently, the Canadian Guideline for Safe and Effective Use of Opioids for Chronic Non-Cancer
Pain, the guideline created for Canadian physicians around opioid prescribing, is not specific for the needs of emergency physicians. The guideline is focused on the needs of primary care providers with ongoing follow-up of patients, which is not the reality of the ED setting. Physicians acknowledge that the guideline does not apply to acute care and even specifically call for acute care facilities to "develop policies to provide guidance on prescribing opioids for chronic pain to avoid contributing to opioid misuse or diversion." 5 This behooves us to review the evidence and create a standardized approach specific for the ED environment.

For years, physicians were taught that effective pain management was often dependent on the initiation of opiate-based treatments. This erroneous approach had significant negative consequences. Addiction can develop quickly and poses a far greater threat than was once believed. ${ }^{6}$ Several studies show that between $4 \%$ and $35 \%$ of patients on long-term opioid therapy have an opioid-use disorder. ${ }^{7-11}$ Some patients may be highly motivated to seek opioids from physicians, but addiction in itself creates a terrible cycle of dependency and drug-use escalation that must be addressed. ${ }^{12}$ Recent guidelines from the Centers for Disease Control and Prevention (CDC) have popularized this issue and given incentive for all physicians to adopt sustainable strategies for chronic pain management. ${ }^{13}$

Although there are currently no national data for prescription opioid-related mortality, provincial data reveal that rates of prescribing and of opioid-related mortality are closely related. In Ontario, deaths have nearly tripled over the last decade. ${ }^{14}$ Furthermore, from 2006-2013, there was an almost 250\% increase in ED visits for opioid-related withdrawal, overdose,

From the *Department of Medicine, †School of Medicine, and $¥$ Department of Family Medicine, Public Health and Preventive Medicine, Queen's University, Kingston, ON.

Correspondence to: Julia Lew, Queen's University, 15 Arch Street, Kingston, ON K7L 3N6; Email: julia.lew@queensu.ca 
intoxication, and psychosis. ${ }^{15}$ Ontario is not alone in this struggle. In British Columbia, a public health emergency was declared this year over recent surges in overdose deaths, with 371 deaths in the first 6 months of 2016. ${ }^{16}$ Alberta has recently experienced a devastating fentanyl outbreak with 272 deaths in 2015 , double the 2014 death toll. ${ }^{17}$ Although it is unclear whether this is related to illicit imported drugs or those prescribed within Canada, it is evident that opioid prescribing has contributed to increased availability and abuse. ${ }^{18}$

The College of Physicians and Surgeons of British Columbia has shown leadership by developing opioid prescribing guidelines, which can serve as a framework for other provinces and territories to develop their own guidelines. They clearly recommend that "all emergency rooms ... have a consistent policy around the prescribing (and dispensing) of opioids." 19 On a national level, the Canadian Association of Emergency Physicians (CAEP) and hence EDs across Canada can take the lead by developing consistent guidelines for opioid prescribing.

Emergency physicians have already established themselves as successful advocates for issues such as injury prevention and wait-time reduction. Through CAEP we can use this expertise to collaborate nationally and develop standardized guidelines that can be adopted by local EDs. To create compassionate guidelines based on best practice, we must bring together expertise within our discipline as well as experts in chronic pain, addiction, and palliative care, including those who can assess the unique situation of pediatric cases in general EDs. Guidelines will need continuous quality improvement to monitor effectiveness, and opioid prescribing rates could be used as a quality indicator.

In the ED, we are often asked to fill or renew opioid prescriptions. Providing adequate pain management has become an increasingly important goal of emergency care; however, safe prescribing can be difficult due to limited continuity of care and a lack of access to patients' records. One study found that $29 \%$ of patients who developed serious addictions after medical exposure to opioids received their initial prescription in the ED. ${ }^{20}$ Clearly, it is challenging to safely prescribe opioids in an acute care setting, and guidelines could help standardize practices. Emergency physicians are also at the front line for treating overdose victims, putting us in a unique position to understand the magnitude of this issue. We must not be a part of the problem by contributing to the quantity of opioids circulating in communities, but instead be active participants in finding solutions.

Prescribing guidelines are only one part of a comprehensive solution. Harm reduction strategies are an important means to reduce morbidity and mortality and could be incorporated into prescribing guidelines, as in the BC Guidelines. CAEP and emergency physicians have a social responsibility to advocate for many of the key facets of a sustainable solution: more funding for addiction services, quicker access to primary care and community resources, physician accessible prescription drug monitoring programs, easier entry to chronic pain, and palliative services. Furthermore, mental health and concurrent disorders are often prevalent in this population and require comprehensive approaches that are not always available in physicians' day-to-day pain management. Prescribing guidelines could help promote the multidisciplinary treatment that is required to sustainably address the propensity for opioid-related morbidity and mortality.

Canada needs a consistent and persistent approach to prescribe opioids responsibly. As a key part of a comprehensive solution, prescribing guidelines in EDs will promote standardization and empower physicians to deny inappropriate prescription requests. We must be aware of the serious implications of our prescriptions, which have led to thousands of premature deaths. EDs are faced with all of the complications of the opioid epidemic and are in a unique position to advocate for change and to protect Canadians from the risks of prescription opioids.

Keywords: opioids, prescribing guidelines, public health

Competing interests: None declared.

\section{REFERENCES}

1. United Nations Office on Drugs and Crime. World drug report. New York: United Nations; 2016. Available at: https://www.unodc.org/doc/wdr2016/WORLD_DRUG_ REPORT_2016_web.pdf (accessed October 8, 2016).

2. ORbeOK Canada. Opioid addiction and recovery; 2015. Available at: http://www.orbeok.ca (accessed October 8, 2016).

3. Canadian Cancer Society. Cancer statistics at a glance. Toronto: Canadian Cancer Society; 2016. Available at: http:// www.cancer.ca/en/cancer-information/cancer-101/cancer-stati stics-at-a-glance/?region=on (accessed October 8, 2016).

4. Transport Canada. Motor vehicle traffic collision statistics. Ottawa: Ministry of Transport; 2016. Available at: https://www.tc.gc.ca/media/documents/roadsafety/cmvtcs2014_ eng.pdf (accessed October 8, 2016). 
5. Michael G. DeGroote National Pain Centre. Canadian Guidelines for Safe and Effective Use of Opioids for Chronic Non-Cancer Pain. Canada: National Opioid Use Guideline Group; 2010. Available at: http://nationalpaincentre.mcmas ter.ca/opioid/ (accessed October 8, 2016).

6. Ballantyne JC, Shin NS. Efficacy of opioids for chronic pain: a review of evidence. Clin 7 Pain 2008;24(6):269-78.

7. Boscarino JA, Rukstalis MR, Hoffman SN, et al. Prevalence of prescription opioid-use disorder among chronic pain patients: comparison of the DSM-5 vs. DSM-4 diagnostic criteria. 7 Addict Dis 2011;20(3):185-94.

8. Boscarino JA, Rukstalis MR, Hoffman SN, et al. Risk factors for drug dependence among out-patients on opioid therapy in a large US health-care system. Addiction 2010;105(10): 1776-82.

9. Fleming MF, Balousek SL, Klessig CL, et al. Substance use disorders in a primary care sample receiving daily opioid therapy. 7 Pain 2007;8:573-82.

10. Banta-Green CJ, Merrill JO, Doyle SR, et al. Measurement of opioid problems among chronic pain patients in a general medical population. Drug Alcohol Depend 2009;104:43-9.

11. Becker WC, Fiellin DA, Gallagher RM, et al. The association between chronic pain and prescription drug abuse in veterans. Pain Med 2009;10:531-6.

12. Finestone HM, Juurlink DN, Power B, et al. Opioid prescribing is a surrogate for inadequate pain management resources. Can Fam Phys 2016;62(6):465-8.

13. Centers for Disease Control and Prevention. CDC guideline for prescribing opioids for chronic pain. Atlanta; 2016. MMWR Morb Mortal Wkly Rep 2016; 65(1): 1-49, errata 65(11): 295.
14. Kingston, Frontenac, Lennox \& Addington Public Health Informatics. Ontario coroner opioid death slides. Kingston: Kingston, Frontenac, Lennox \& Addington Public Health; 2016. Available at: http://www.kflaphi.ca/presentations/ (accessed October 8, 2016).

15. National Advisory Committee on Prescription Drug Misuse. First do no harm: Responding to Canada's prescription drug crisis. Ottawa, Ontario: Canadian Centre on Substance Abuse; 2013.

16. British Columbia Coroner Services. Illicit drug overdose deaths in BC: January 1, 2007-June 30, 2016. Vancouver: Ministry of Public Safety and Solicitor General; 2016. Available at: http://www2.gov.bc.ca/assets/gov/public-safety-andemergency-services/death-investigation/statistical/illicit-drug.pdf (accessed October 8, 2016).

17. Etches, N Fentanyl and Take Home Naloxone: The Alberta Experience. Calgary: Alberta Health Services; 2016. Available at: http://www.albertahealthservices.ca/assets/healthinfo/mh/ hi-amh-thn-presentation-accpa.pdf (accessed October 8, 2016).

18. Nelson LS, Juurlink DN, Perrone J. Addressing the opioid epidemic. 7AMA 2015;314(14):1453-4.

19. College of Physicians and Surgeons of British Columbia. Professional standards and guidelines - safe prescribing of drugs with potential for misuse/diversion. Vancouver: College of Physicians and Surgeons of British Columbia; 2016. Available at: https://www.cpsbc.ca/files/pdf/PSG-Safe-Pre scribing.pdf (accessed October 8, 2016).

20. Butler MM, Ancona RM, Beauchamp GA, et al. Emergency department prescription opioids as initial exposure preceding addiction. Ann Emerg Med 2016;68(2):202-8. 